\title{
Geography Far from Equilibrium
}

\author{
Denise Pumain
}

\begin{abstract}
Geography makes little use of the concept of equilibrium. Unlike economics, geographical inquiry is based on the recognition of differences and asymmetries among regions and civilisations. In this it does not refer to general mechanisms that would be equivalent to the market for fixing prices and equilibrating supply and demand. Early geographers searched for explanations to the great variety of landscapes and ways of life that were observed all over the planet. Modern geographers study both the 'vertical' interactions between societies and their local milieu and the 'horizontal' interactions between cities and regions. This involves two opposing causes of territorial inequalities, spatial diffusion of innovation and urban transition. Whereas diffusion of innovation alone might result in homogeneity, combined with the dynamics of city formation the result is increasing heterogeneity and inequality. The phenomenon of increasing returns with city size is explained by higher population densities and connections multiplying the probability of productive interactions, as well as by adaptive valuation of accumulated assets. While there may be great wealth, in some large urban agglomerations large informal settlements of slums and shanties are still expanding. Global societal evolution is an open process with no fixed asymptotic point in the future: there is no final equilibrium state to reach for the world. Open evolution may hamper the quality of predictions that can be made about the future, but geographical knowledge of past dynamics may help to make forecasts more certain. Powerful analytical tools have been developed in the last five or six decades that greatly improve the quality of geographical work and its ability to provide stakeholders and decision makers with clearer insights for exploring possible territorial futures. Geographical Information Systems are now universally used in all kind of administrations dealing with localised services. Detailed geographical information from many data sources enables a shift from a macro-static view to a micro-macro dynamical view that is necessary for management and planning policies in a non-linear world. As a science geography remains deliberately far from equilibrium.
\end{abstract}

\footnotetext{
D. Pumain $(\bowtie)$

Université Paris I, 13 rue du Four, 75006 Paris, France

e-mail: pumain@parisgeo.cnrs.fr
} 


\section{Introduction}

Geography as an academic discipline tries to meet a splendid but difficult challenge: understanding and explaining how human societies use and transform the earthatmosphere interface for their own survival, reproduction and quantitative or qualitative expansion. In this research program the science of geography makes little use of the concept of equilibrium. Unlike economics, geographical inquiry was based from its very beginning on the recognition of differences and asymmetries among regions and civilisations of the world. At first initiated by curiosity for the accounts and discoveries of travellers and explorers such as Ibn Battuta, Marco Polo, it developed into the creation of scholarly associations and geographical societies that appeared from the middle of nineteenth century. Geographical knowledge also was developed at first for preparing wars, and then for managing and exploiting colonial conquests. It was valued precisely because it supplied knowledge of a variety of resources that were unknown in the country of origin.

So it is not surprising that when geography was set up as a branch of knowledge in universities at the beginning of twentieth century, the first scientists extended this intellectual interest by searching for explanations to the great variety of landscapes and ways of life that were observed all over the planet. Sources of differences and strangeness were at first thought to reflect different conditions of climate and topography, as well as the ability of societies to exploit them. Subsequently the geographical situation relative to major routes and spatial concentrations of power and population was considered to be a major explanatory factor, especially centerperiphery constructions at all geographical scales that are continuously changing and never were conceived as being in equilibrium. Even today, where one could think of a possible unification of the world through tourism and business travel, and where global and instant diffusion of communication world news tends to diminish the strangeness of distant countries, geographers still maintain a strong belief that 'space matters', and there is nothing like a 'flat world'. Despite the dominant cultural industries, the aspirations to imitate lifestyles of the richest, and the apparent ubiquity of information flows through Internet, new differences emerge from the complex dynamics of territorial systems. These include path dependence effects that lead to accentuated disparities that work against homogenisation.

As a science, geography remains deliberately far from equilibrium. Therefore, geographical models that help decision makers in their choices for developing territories or undertaking specific activities always share two major characteristics: (1) they never are considered as providing optimal solutions, but leave open a plurality of possible future paths, and (2) whatever the scale under consideration, they always are contextualised, to a given specific place or situation. Consequently, geographical models and interpretations can favourably counterbalance inadequate representations based on a concept of general equilibrium. 


\section{Local or Temporary Stabilities Instead of General Equilibrium}

Due to the widespread influence of mechanistic Newtonian equilibrated models imported into all sciences, the 'classical' geographical schools in Europe and America were not totally immune to the temptation to identify situations of equilibrium. Even so,they were deeply influenced by Darwinism and evolutionary concepts. One could perhaps detect equilibrium ideas in the regional descriptions of the first half of twentieth century, in areas of human geography that considered mostly agrarian societies to be more or less stable genres de vie adapted to particular conditions of a given natural milieu, with recognisable original landscapes and combinations of economic productions and cultural features. A similar temptation would be to interpret some work in physical geography as using equilibrium concepts, e.g. when botanical geography elaborated the concept of 'climax' for defining the persistent adaptation of a subset of species to local conditions of climate, relief and soil. As another example in geomorphology a theory relying on balanced processes was conceived by the American geographer Davis [2] introducing the concept of 'erosion cycle'. According to his view, the surging of mountains due to tectonic uplift was normally followed by stream erosion reducing the landscape to a flat plain at an altitude close to sea-level. Indeed his epistemological reference is an evolutionary theory following a mixture of Darwinian or Lamarckian conceptions.

Among most geographers there remained a strong sense of the diversity of the world, and a desire to explain it. A very simplified version of the history of geography emphasises two possible sources of explanation that were more or less successively explored.

At first, the diversity of local 'natural' conditions of climate, topography and soil was thought to be the reason for a variety of landscapes and ways of life. Types and abundance of vegetal and animal resources, their exploitation for sustaining life, and local geology providing materials for building houses were suggested as determining production factors to explain the unequal success of different regions. 'Success' was usually as measured by population densities, directly similar to the concept of fertility rent by Ricardo [9]. Here the notion of equilibrium is often used, in a metaphoric sense, to identify more or less stable combinations of population densities, types of human habitat and systems of resource exploitation, mainly for agricultural systems linked with specific 'terroirs' and local climates.

But of course in this explanation geographers do not refer to any general mechanisms that would be equivalent to the market for fixing prices and equilibrating supply and demand. The possible balance between human densities and local resources is regularly revised by changes in production and organisational techniques that are periodically driven by demographic pressure or famine events. There is never any mention of a possible convergence between economies that are evaluated at different levels of geographical success. The inquiry is directed towards avoiding a too simplistic 'determinism' and enriching the explanation of inequalities 
by considering different ways of societal organisations that enable more or less intensive types of production.

From the 1950s, a second source of explanation was more systematically investigated by exploring not only the 'vertical' interactions between societies and their local milieu, but also the 'horizontal' interactions between cities and regions. The diversity of geographical situations respective to circulation axes (large valleys, maritime bays and river estuaries for harbour sites, road and railway networks, airline hubs), to existing concentrations of population and activities (center-periphery models) and spatial discontinuities (political or economic borders) is considered as constraining the potential for local developments, sometimes in a much stronger way than the available resources in the local environment.

This explanatory path, sometimes named spatial analysis, roughly identified two major processes that may have contradictory effects on territorial inequalities: spatial diffusion of innovation, and urban transition.

The trend towards spatial diffusion of innovation could result in a convergence between places where a new and profitable activity or technological device or feature of the way of life emerge and places where they are imitated and adopted later. Indeed, many characteristics of 'modernisation' have been widely diffused in very large parts of the world. For instance, it could be concluded that a major transition, the demographic transition, has transformed the human condition through the diffusion of health care and reproduction practices, from an ancient 'equilibrium' with high fertility and mortality rates and short life expectancy towards a new one with low fertility and mortality rates and much longer life expectancy. However, this demographic transition over two centuries has also completely changed the size of world population, doubling it during the last 50 years and even if stabilisation is predicted for the middle or end of the present century this can hardly be conceived as the effect of any 'equilibrium' between human societies and their resources. Meanwhile, the temporal delay in the process between more advanced countries and those where the transition is occurring later and faster has dramatically modified the spatial distribution of population of the world by increasing the proportion of Asia and Africa compared to Europe and America.

Indeed, the second major transition that occurred in the world during the last two centuries, the so-called urban transition, while networking almost all places on earth has created entirely new inequalities in population densities, wealth and living conditions between the towns and cities that have proliferated across the planet. The spatial distribution of world population has been dramatically transformed at all scales of observation: between urban places and rural areas; city centres and their peripheries; and attractive regions and abandoned ones. The ranking of cities in terms of demographic weight is more volatile: although New York and Tokyo remain today among the largest urban centres, several other major urban concentrations above twenty millions inhabitants have emerged, especially in China around Shanghai, Beijing-Tianjin or Guangzhou and in India in the urban regions of Delhi, Mumbai and Kolkata. The urban world however does not generate chaos as is sometimes lamented, but certainly it drives the world on a path that goes further and further away from any 'equilibrium'. 


\section{Increasing Inequalities with Urban Development}

If we accept for a while to adopt the vocabulary of economic science that implicitly refers to the concept of equilibrium, we could suggest a principle of geographical evolution as a possible global convergence, e.g. the availability of some technologies, health care, life expectancy, aspects of the ways of life, and information diffusion. However, whatever the scale, local or global, there is no possible reference to any equilibrium of any sort since, as in biology (although much more rapid), global societal evolution is an open process with no fixed asymptotic point in the future: there is no final equilibrium state to reach for the world, and at local levels quantitative as well as qualitative differences between places are expanding.

\subsection{Asymmetries in the Accumulation Process}

Geographers call 'urban transition' the universal historical change in the way human societies are colonising the earth. There was a phase transition from a rural to urban world. Rural settlements linked mainly to the development of agriculture since Neolithic times generated a human habitat made of small concentrations. These population nodes were similar in size (a few hundreds to a few thousands inhabitants at maximum) and widely scattered all over the surface of the earth. By contrast, urban settlements are a much more concentrated and heterogeneous way of inhabiting the planet including agglomerations of much more diverse sizes between $10^{3}$ and $10^{7}$ inhabitants. Urbanisation seems an ineluctable process that has remained a latent trend for seven millennia but has accelerated greatly during the last two centuries, since about 1800 in the now developed countries and 1950 in the rest of the world. While the rural economy was based on using local resources and human and animal energy, the hierarchised systems of cities depends on exchanging resources over much longer distances and structuring networks of secondary and tertiary activities, manufacturing and services, that have become more and more complex.

Why and how have such huge concentrations of population and wealth become possible? They were generated mainly through incremental historical processes of accumulation relying on persistent asymmetries. Among them, the political domination of 'centres' of power established through societal organisations of various kinds and the inequitable pricing of goods and wages that was often linked to it. The 'increasing returns with city size' now widely acknowledged, even by economists, is generated by higher populations densities and connections multiplying the probability of productive interactions. Nowadays, two trends are reinforcing the hierarchical qualitative and quantitative inequalities among cities: the higher level of complexity of activities (functional diversity and historical advances in technologies) and the skill of the labor force (sometimes referred to as 
higher 'creativity') are attracting profitable innovation to the largest urban centres where the increased speed of transportation systems short-circuit the smallest settlements.

From a geographical and historical perspective it may even be argued that spatial inequalities are a resource that sustains the growing dynamics of the system. Globally, it seems clear that wealth can be created by integrating populations of former poor countries (but not yet the poorest) into the consumption markets. Increased land values are generated at the peripheries of metropolitan areas of emergent economies by incorporating cheaper agricultural or nomadic land into the urban realm, where parcels are sold at prices that are tens to hundreds times higher than before.

\subsection{Increasing Divergence in Accessibility as Transportation Speed Increases}

Another source of the creation of inequalities between geographical places is the increase in transportation speed that has been especially effective and spectacular during the last two centuries. Regular stagecoaches, then trains and then airplanes have dramatically reduced the time for connecting the places. In parallel, the cost of transportation has been lowered and the mobility of people and goods has considerably increased. But if every location has gained in accessibility, there are growing inequalities in the accessibility level of places: as rapid transport systems are organised in networks having less and less nodes the more rapid they are, the more the differences in transportation times from one point to another one are increasing. The world in space-time terms is together becoming smaller, shrinking and shriveling (Waldo Tobler [10]). There is an historical shift from a world of homogeneous slowness towards a world of much more differentiated swiftness.

Inequalities appear to be growing at world scale but are sometimes difficult to measure according to the heterogeneity of cultures and statistical systems. Despite this, two examples of increasing differences can be quoted as examples of economic divergence at lower geographical scales. In the European Union where compensation systems are conceived for reducing inequalities, it was demonstrated that if the general economic level had a converging trend at the scale of member states, the gap in wealth production and consumption would increasing between places at regional level [5, 6]. At a much more local level, it is increasingly observed in large urban metropolitan areas that there are growing social inequalities leading to higher social fragmentation and steeper price gradients in the richest metropolises of the world. Be that as it may, in some large urban agglomerations of the poorest countries, in Africa or South-East Asia, large informal settlements of slums and shanties are still expanding, leading the sociologist Mike Davis to write his book Planet of Slums, whose French title Le pire des mondes possibles translates as 'the worst of possible worlds' [3]. 


\subsection{Continuous Proactive Adaptation in an Open Evolution}

Urban resilience is often mentioned as desirable in policies aimed at sustainable development, including policies in favour of economic growth, social cohesion and preservation of resources for the future generations. But the process towards urban resilience is not the homeostasis that would mean coming back to some equilibrium: it is on the contrary a continuously adaptive process inducing permanent changes in the quantitative and qualitative aspects of urban development and urban life. Such a dynamic is self-sustained by the positive feedback loops linking urban accumulation and societal innovation. The emulation between urban actors aiming at maintaining or increasing the value of their local assets drives them also to imitate or anticipate the innovations of all kinds that are created in other places. It is a permanent constraint on their decisions for adapting and innovating because otherwise there is a risk of losing value for their previous achievements.

Such dynamic properties are interdependent because tightly connected urban systems generate an open evolution that is full of uncertainties. It is sometimes difficult to understand the discrepancy between the intentions of individual actors who try to optimise their action (often inspired by equilibrium theories of influential economists!) and the collective outcome of their work that is sometimes revealing counterintuitive or even 'perverse' effects. As a consequence, there are 'bifurcations' in the evolution of territories at local level such as the long decay or very difficult recovery over many decades of specialised cities that were among the richest during the first and second industrial revolution. Examples include Detroit linked to the automobile manufacturing, or the Ruhr region specialised in coal extraction and steel industries. Inside cities, some neighbourhoods loose attraction and value whereas others, especially close to waterfronts, central business districts or formerly abandoned industrial zones were happily renovated and consequently gentrified. At upper geographical scales, bifurcations are transforming the fate of large territories as in the case of the so called BRICS countries including Brazil, Russia, India, China and South Africa that shared very rapid growth rates since the end of twentieth century leading the group to institutionalise in 2009 and 2011 [7].

Many other transformations can be expected in the future evolution of the world in its different parts. The fact that it is an open evolution may hamper the quality of predictions that can be made about its future, but the geographical knowledge of its past dynamics may help to reduce the uncertainties of forecasts and indicate some more promising directions. Powerful analytical tools have been developed in the last five or six decades that greatly improve the quality of geographical work in its ability to provide stakeholders and decision makers with clearer insights for exploring possible territorial futures. 


\section{Geographical Tools for Managing and Anticipating the State of the World}

Many concepts of modern geography may be used for guiding decision making. Geographical science, knowledge and skills, could be used more intensely for thinking about policies of territorial development and habitat or landscape management.

A first feature is a sense of 'place'. Because geographers are convinced of the intrinsic diversity of the world and because they share an evolutionary perspective that recognise the effectiveness of path dependence in spatial changes, they will always emphasise the importance of 'place' and this helps stop them applying undifferentiated solutions independently of the local situations. This does not imply the irreducible singularity of each territory or local problem, but is merely a plea for adapting models and policy processes to identify peculiarities that can improve the impact of decisions.

In this respect, huge progress has been made in equipping geographers with relevant tools. Computer-based Geographical Information Systems are now universally used in all kind of administrations dealing with localised services. Since emerging in the nineteen seventies they have been progressively enriched with analytical tools for spatial analysis that refine, for instance, the computation of distances from as-the-crow-flies measurements to sophisticated estimations of travel time combining several transportation modes including waiting times. Such measurements of accessibility can be applied to all kind of services and be adapted for subpopulations, building high-performance instruments for solving locationallocation problems.

Mapping is essential in land and regional planning. Recent progress in developing dynamic models in silico enables simulation of a wide variety of scenarios. Estimates of societal needs are translated into projected changes in dedicated land surfaces allocated in different places according to the most probable land-use transitions. This uses computerised visualisation tools with 'cellular automata' to display the possible local future consequences of planning decisions. These models can include many local bifurcations that are displayed as animated maps, which helps in understanding the non-linear effects of urban growth or spatial movements.

The usefulness of Geographical Information Systems is linked to their power to integrate many different data sources, including satellite images, statistical services, and new sources such as static or mobile sensors in the environment [4]. When coupled with adapted simulation models the recent availability of these 'Big Data' has extended the capacity of these geographical tools to represent emergent phenomena between micro-level events or behaviour and spatial structures at macrolevel. Thus geocomputation has become a widely developed activity that is now able to generate series of validated and reproducible dynamic models using, for instance, open simulation platforms such as OpenMOLE [8] for reconstructing the development of urban systems at different geographical scales in a variety of countries, and the agent-based Simpop models (http://www.simpop.parisgeo.cnrs. fr). 
Indeed, from scientific geographical knowledge including the spatial dynamics of innovation, stylised facts of spatial evolution have been identified and make part of future transformations predictable. An example is the delineation of probable gradients of gentrification inside wealthy urban areas, following a process reducing the 'rent gap' between the urban core and the previously less favoured neighbourhoods. Another example is the evolving spatial international division of labour between the rich and poor countries: after the rise of the GDP level per inhabitant in emergent countries, the wages of local workers are increasing, and manufacturing activities migrate towards poorer countries. For example, Chinese enterprises have already located some of their production units in Vietnam, Indonesia or Ethiopia.

Other applications of geographical knowledge can be found in the domain of epidemiology. For example, [1], commenting on the rapid victory over the SARS epidemic due to the network information system established by the WHO, highlight "the exploratory power of animated and interactive maps as spatial surveillance tools ... to reveal local and global dynamics of a given epidemic, ... underline the complexity of the epidemic process and the high variability of local situations that a 'smooth' global pattern can be composed of. Two crucial parameters - amongst many - we need to control before building any diffusion model. Anyway, a major GIS shift has to be achieved if we want to carry on, from data management to data analysis ... leading to more realistic and efficient identification of underlying patterns" [1].

As Mike Batty often recalls, detailed information about geographical processes helps in shifting from a macro-static view to the micro-macro dynamics view needed for correctly advising management and planning policies in a non-linear world.

Open Access This chapter is distributed under the terms of the Creative Commons Attribution 4.0 International License (http://creativecommons.org/licenses/by/4.0/), which permits use, duplication, adaptation, distribution and reproduction in any medium or format, as long as you give appropriate credit to the original author(s) and the source, provide a link to the Creative Commons license and indicate if changes were made.

The images or other third party material in this chapter are included in the work's Creative Commons license, unless indicated otherwise in the credit line; if such material is not included in the work's Creative Commons license and the respective action is not permitted by statutory regulation, users will need to obtain permission from the license holder to duplicate, adapt or reproduce the material.

\section{References}

1. Banos, A., Lacasa, J.: Spatio-temporal exploration of SARS epidemic. Cybergeo: Eur. J. Geogr. 480 (2007). http://cybergeo.revues.org/12803

2. Davis, W.M.: The rivers and valleys of Pennsylvania. Natl. Geogr. Mag. 1, 183-253 (1889)

3. Davis, M.: Planet of Slums. Verso, London (2006)

4. Longley, P.A., Goodchild, M.F., Maguire, D.J., Rhind, D.W.: Geographic Information Science and Systems. Wiley, Hoboken (2015)

5. Piketty, T.: Le Capital au XXIe siècle, 950 pp. Seuil, Paris (2013)

6. Puga, D.: The rise and fall of regional inequalities. Eur. Econ. Rev. 43(2), 309-334 (1999) 
7. Pumain, D., Swerts, E., Cottineau, C. Vacchiani-Marcuzzo, C., Ignazzi, A., Bretagnolle, A., Delisle, F., Cura, R., Lizzi L, Baffi, S.: Multi-level comparison of large urban systems. Cybergeo 706 (2015). http://cybergeo.revues.org/26730. doi:10.4000/cybergeo.26730

8. Reuillon, R., Leclaire, M., Rey-Coyrehourcq, S.: OpenMOLE, a workflow engine specifically tailored for the distributed exploration of simulation models. Futur. Gener. Comput. Syst. (IF:2.639), 29(8), 1981-1990 (2013). http://www.openmole.org/files/FGCS2013.pdf

9. Ricardo, D.: On the Principles of Political Economy and Taxation. John Murray, London (1817)

10. Tobler, W.: The world is shriveling as it shrinks. Invited Presentation. A \& M College Station, Texas (2001). http://www.geog.ucsb.edu/ tobler/presentations/The-shriveling-world.pdf 